\title{
Study of Chemical Additives in the Cementation of Radioactive Waste of PWR Reactors
}

\author{
Vanessa Mota Vieira ${ }^{*}$, Clédola Cássia Oliveira de Tello \\ Nuclear Technology Development Center, National Nuclear Energy Commission, Brazil
}

Copyright $(2016$ by authors, all rights reserved. Authors agree that this article remains permanently open access under the terms of the Creative Commons Attribution License 4.0 International License

\begin{abstract}
Cementation is a very useful process to solidify radioactive wastes. Depending on the waste it can be necessary to use of chemical additives (admixtures) to improve the cementation process and its product. Admixtures are materials, other than cement, aggregate and water, that are added either before or during the mixing to alter some properties, such as workability, curing temperature range, and setting time. However there are a large variety of these materials that are frequently changed or taken out of the market. In this changeable scenario, it is essential to know the commercially available materials and their characteristics for use in the cementing of radioactive waste. In this research the effects of chemical admixtures in the solidification process has been studied. For the tests, it was prepared a solution simulating the evaporator concentrate waste, cemented by two different formulations, and three chemical admixtures from two manufacturers. The tested admixtures were accelerators, set retarders and superplasticizers. The experiments were organized by a planning factorial $2^{3}$ to quantify the effects of formulations, of the admixtures, its quantity and manufacturer in properties of the paste and products. The measured parameters included the density, the viscosity and the setting time of the paste, and the product compressive strength. As future work the leaching test will be performed. The parameter evaluated in this study was the compressive strength for a curing time of 28 days, is considered essential security issues relating to the handling, transport and storage of cemented waste product. The results showed that the addition of accelerators improved the compressive strength of the cemented products.
\end{abstract}

Keywords Radioactive Waste, Cementation, Chemical Admixtures, Compressive Strength and Density

\section{Introduction}

According to the International Atomic Energy Agency (IAEA) nuclear-power is responsible for about $17 \%$ of world electricity needs. This percentage tends to increase with the construction of new plants, mainly in developing countries (China, India and others). It is a clean energy that does not emit gases responsible for the increase of global warming or emit other toxic products. Nuclear power plants occupy relatively small areas; they can be installed close to consumer centers which reduces the cost of energy distribution. Additionally they are independent on climatic factors for their operation [1].

The Brazilian Nuclear Program (PNB) forecasts an increase in the use of nuclear energy to generate electricity, with the construction of at least four more nuclear power plants in the Northeast and Southeast Brazil by 2030 [2]. In Brazil, there are currently two PWR (pressurized water reactor) reactors, which use enriched uranium and are moderated and cooled by pressurized light water. In these reactors the boron is used to control the fission reactions. From the reactor operation is generated an aqueous solution with boron, which is treated in the evaporator for volume reduction. This process produces a concentrate with approximately $12.5 \%$ of boron acid, classified as radioactive waste [3].

Wastes of low and intermediate level of radiation are solidified by incorporation in cement in order to prevent or hinder the release of contaminants from the waste product to the environment during storage, transport and disposal, ensuring its stability and durability. In the multi-barrier repository concept, the lower is the release of radionuclides from the product, the lower are the requirements for the repository barriers and the safer will be the disposal. Cement has been used as the main matrix to immobilize these radioactive wastes, although the bitumen and polymers are also studied. The choice of the matrix will depend on many factors, such as the waste type and its form, its activity and radionuclides, the requirements of the repository, as well as economic, engineering and security aspects [4].

Portland cement is widely used for liquid waste solidification, due to its ease of acquisition; there is a large experience in its use and the capacity to be processed at room temperature. The final cemented product must meet three basic criteria to ensure safe handling in subsequent steps of 
radioactive waste management and acceptance in repositories; these criteria include mechanical strength, impermeability, and stability [1].

The direct solidification of wastes containing boric acid with Portland cement is not adequate due to the retarding effect caused by the waste acidity and the action of borate ion on the setting of the cement. Thus the cemented product containing boric acid wastes has a quality that ranges from poor to good. To improve the conditions of cementation process and the physical and chemical properties of the solidified product; the chemical and minerals additives are used [5].

In this work three chemical additives were tested: superplasticizer, setting retarders and setting accelerator from two different manufacturers, using two formulations for cementation of evaporator concentrate.

The main objective is to study the effect of each type of chemical additive, its quantity, the manufacturer and the formulation (ratio of waste / dry mix) in the cementation process of the concentrate from the evaporator, checking their effects on the cement paste and cemented product quality through the evaluation of their properties such as compressive strength, viscosity, density, and setting time.

Compressive strength tests are presented in this paper in samples at an age of 28 days. This is an essential parameter to security issues related to handling, transport and storage of cemented waste products. It is desirable that the value for this property are as high as possible, since any fragility of the product would allow the dispersion of contaminants from the waste and could cause a deterioration in storage, bringing risks to humans and the environment [6].

\section{Materials and Methods}

\subsection{Materials}

Portland cement CP V-ARI, a high-early-strength cement, was used, the main characteristic is to provide high compressive strength values at an early period, usually a week or less. The development of high early strength is achieved by using a different dosage of limestone and clay in the production of clinker, as well as by the finer grinding of the cement, so that, when reacting with water, it faster reaches high resistances.

Microsilica. It is a by-product of silicon metal, iron silicon and other alloys of iron and consists of very fine particles of silica, forming a fine powder whose colors vary according to its origin. It is used in a proportion of $10 \%$ compared to the weight of cement, here called the dry mixture.

Accelerators. It reduces the time needed to cure time of the cement, which causes an increase in the compressive strength at low temperatures and reduces demolding time

Set retarders. It increases the start time and end of the cure the cement, maintaining the workability at high temperatures, augmenting the compressive strength at older ages, slowing the heat of hydration and expanding the application time.
Superplasticizers. These provide high resistance to the cemented products with early ages ( 24 hours), making the mixture fluid and with high workability. Due to the reduction of the capillarity, the cemented product becomes more waterproof, durable, and resistant.

Simulated waste. A solution was prepared to simulate the concentrate from the evaporation process. The concentration of boric acid in the solution was approximately $12.5 \%$.

\subsection{Experimental Planning}

The chemical additives (accelerators, set retarders and superplasticizers) were separately tested. For each one the experiments were organized by planning factorial $2^{3}$ with replicates. The variables (or factors) studied were: manufacturers ( $\mathrm{H}$ and $\mathrm{S}$ ), quantities (the minimum and maximum ones specified by the manufacturers) and formulations of the pastes (A and B). Generally, when the factor is quantitative, the level below was that of lowest value, while the high level was the highest value. In the case of qualitative factors such as the manufacturer, they were chosen arbitrarily. The experiments were organized according to Table 1 .

Table 1. Planning factorial $2^{3}$ for the experiments with chemical additives.

\begin{tabular}{|c|c|c|c|}
\hline \multirow{2}{*}{ Test } & \multicolumn{3}{|c|}{ Variable } \\
\cline { 2 - 4 } & Formulation* & Quantity additive & Manufacturer** \\
\hline 1 & - & - & - \\
\hline 2 & - & - & + \\
\hline 3 & - & + & - \\
\hline 4 & - & + & + \\
\hline 5 & + & - & - \\
\hline 6 & + & - & + \\
\hline 7 & + & + & - \\
\hline 8 & + & + & + \\
\hline
\end{tabular}

* $\mathrm{A}(-) \mathrm{B}(+)$

** $\mathrm{S}(-) \mathrm{H}(+)$

The experiments were randomly performed so that the effects of external factors did not influence the evaluation of the results. Admixtures called "Blank" were prepared without any additive, also performed in duplicate. A total of 52 batches were carried out, included the blank mixtures and eight experiments in duplicate of each admixtures under conditions as homogeneous as possible.

\subsection{Preparation of the Cement Pastes and Samples}

Two formulations of the pastes (A and B) were prepared. Formulation A contains a lower quantity of cement and greater quantity of waste, contrasting Formulation B, which contains more cement and less waste.

The dry mixture was prepared with Portland cement CP $\mathrm{V}$-ARI and microsilica in the proportion of $10 \%$ of the cement weight. Then the simulated waste was neutralized 
$(\mathrm{pH} \mathrm{7,0)}$ with calcium hydroxide and mixed with the dry mixture. During the mixture preparation process, the admixture was added, producing homogeneous pastes. After that the samples were molded in metal cylinders (diameter of $5 \mathrm{~cm} \pm 0,1$ and $10 \mathrm{~cm} \pm 0,1$ in height), illustrated in Fig. 1. For each batch eight (08) samples were molded.
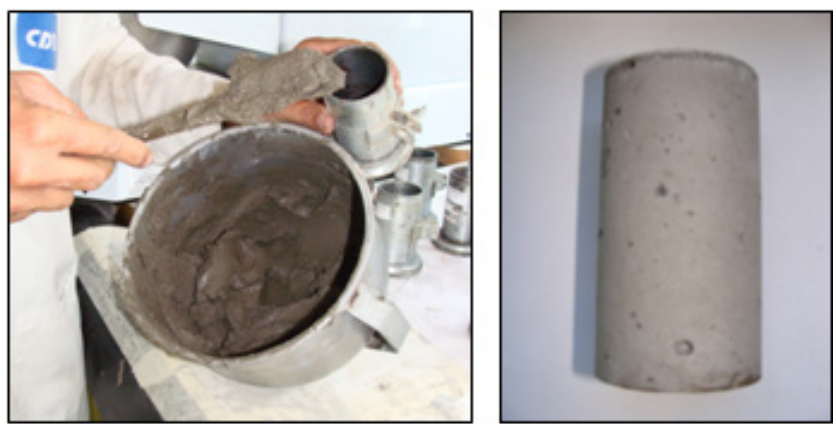

Figure 1. Cement Pastes and Samples.

\subsection{Tests}

For each mixture and samples, the following tests were performed: viscosity, setting time, density of the product and pastes, and compressive strength.

A viscometer with a T-spindle, suitable for rheological measures, was used for the evaluation of viscosity. The setting time of the pastes was measured by using the "Vicat needle" automatic apparatus. To determine the compressive strength at age of 28 and 90 days of curing, it was used a hydraulic press.

The density of the fresh pasts and of solidified products (samples) were also measured. In Fig.2, the equipment used for the following tests are shown: viscosity, setting time, and compression strength.

\section{Results}

The compressive strength values were organized and a statistical study was made, based on the planning factorial $2^{3}$. It was used MINITAB ${ }^{\circledR}$ software to analyze the results.

\subsection{Set Retarders}

The results obtained from compressive strength at age of 28 days test in products with set retarders are presented in Table 2.

Table 2. Set retarders - Results of compressive strength tests at curing time of 28 days.

\begin{tabular}{|c|c|c|c|c|}
\hline \multirow{2}{*}{ Test } & \multicolumn{3}{|c|}{ Variable } & $\begin{array}{c}\text { Compressive } \\
\text { strength at 28 } \\
\text { days (MPa) }\end{array}$ \\
\cline { 2 - 6 } & Formulation & Quantity & Manufacturer & $14,7 \pm 3,1$ \\
\hline \multicolumn{5}{|c|}{ Blank (-) } \\
\hline 1 & - & - & - & $14,2 \pm 1,2$ \\
\hline 2 & - & - & + & $12,4 \pm 0,2$ \\
\hline 3 & - & + & - & $13,2 \pm 1,0$ \\
\hline 4 & - & + & + & $10,1 \pm 0,4$ \\
\hline & \multicolumn{5}{|c|}{ Blank (+) } & - & $24,3 \pm 1,4$ \\
\hline 5 & + & - & - & $18,0 \pm 5,8$ \\
\hline 6 & + & - & + & $12,9 \pm 3,5$ \\
\hline 7 & + & + & - & $14,7 \pm 0,7$ \\
\hline 8 & + & + & + & $16,1 \pm 0,5$ \\
\hline
\end{tabular}
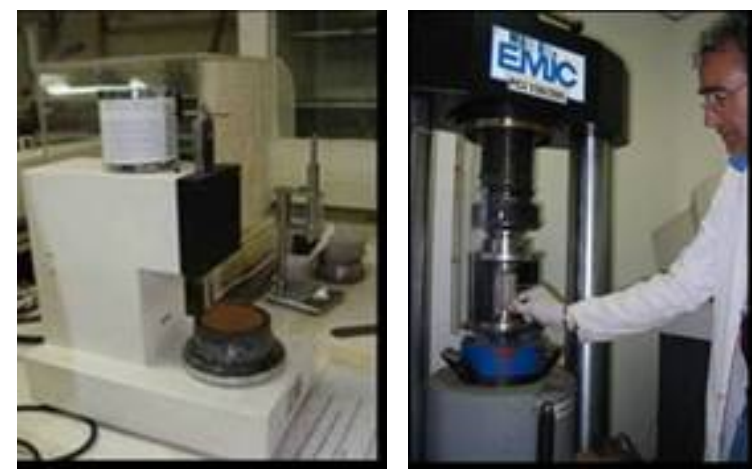

Figure 2. View of the viscosity, setting time and compression strength tests. 
The studies to analyze the effects of factors on the compressive strength when set retarders are used in mixtures are represented in the Fig. 3, 4, and 5. It was concluded that, with a confidence interval of $95 \%$, both formulations and manufacturers have a significant effect on the compressive strength, for a curing time of 28 days. The same happens with the interactions between the manufacturer and the quantity of additive and among the three factors (formulation and manufacturer; formulation).

The use of set retarders for the cementation of Formulation B which contains a higher amount of cement (Tests 5-8) had a positive effect on compressive strength at age of 28 days (Fig. 5), in relation to the Formulation A. It was noted that products with smaller quantities of set retarders had higher compressive strength values, but the effect of the quantity was not significant with a confidence interval of $95 \%$.

The highest value the compressive strength at age of 28 days was found for the combination of factors: Formulation $\mathrm{B}$, smaller quantity of set retarder and Manufacturer S and the lowest value was for Formulation A, greater amount of set retarder and the Manufacturer $\mathrm{H}$.

In all combination, the compressive strength was jeopardized by the retarder, since these values were smaller than those of the blank samples.

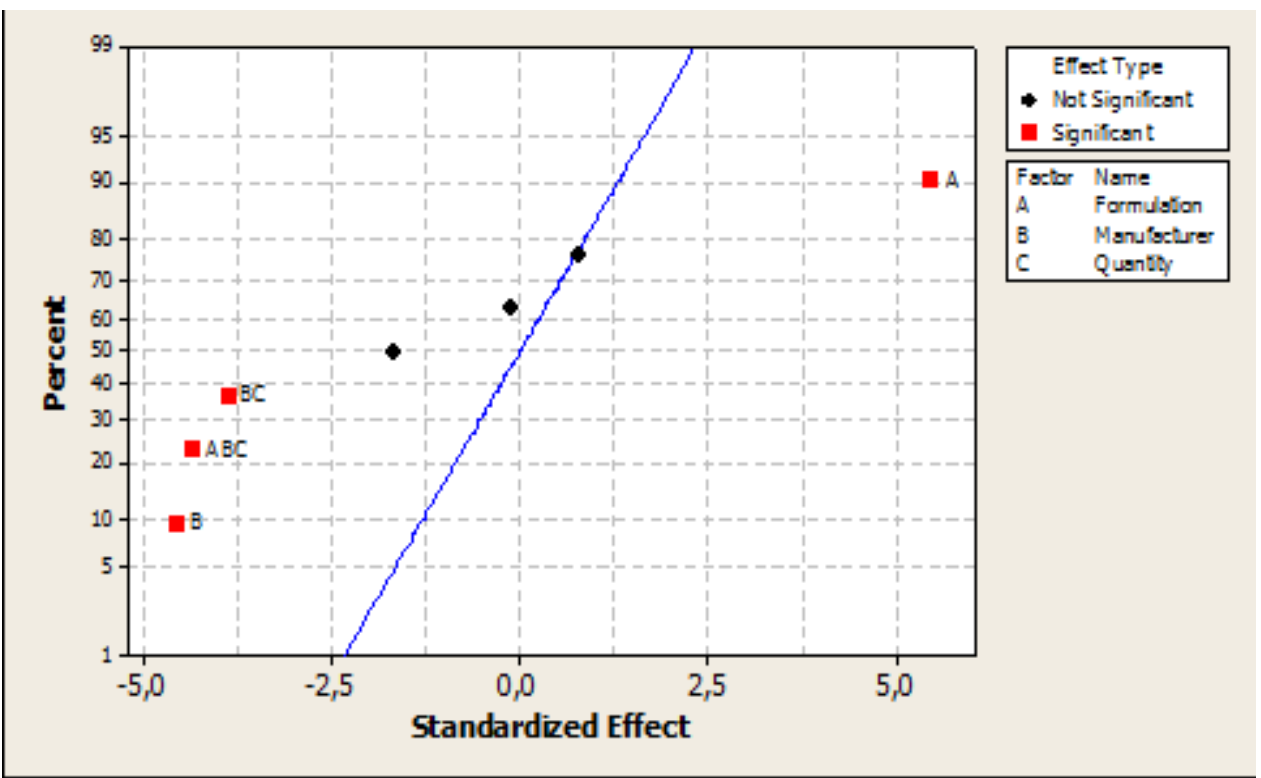

Figure 3. Set Retarder - Analysis of the effects of the variables (factors) and their interactions on the compressive strength, at age of 28 days

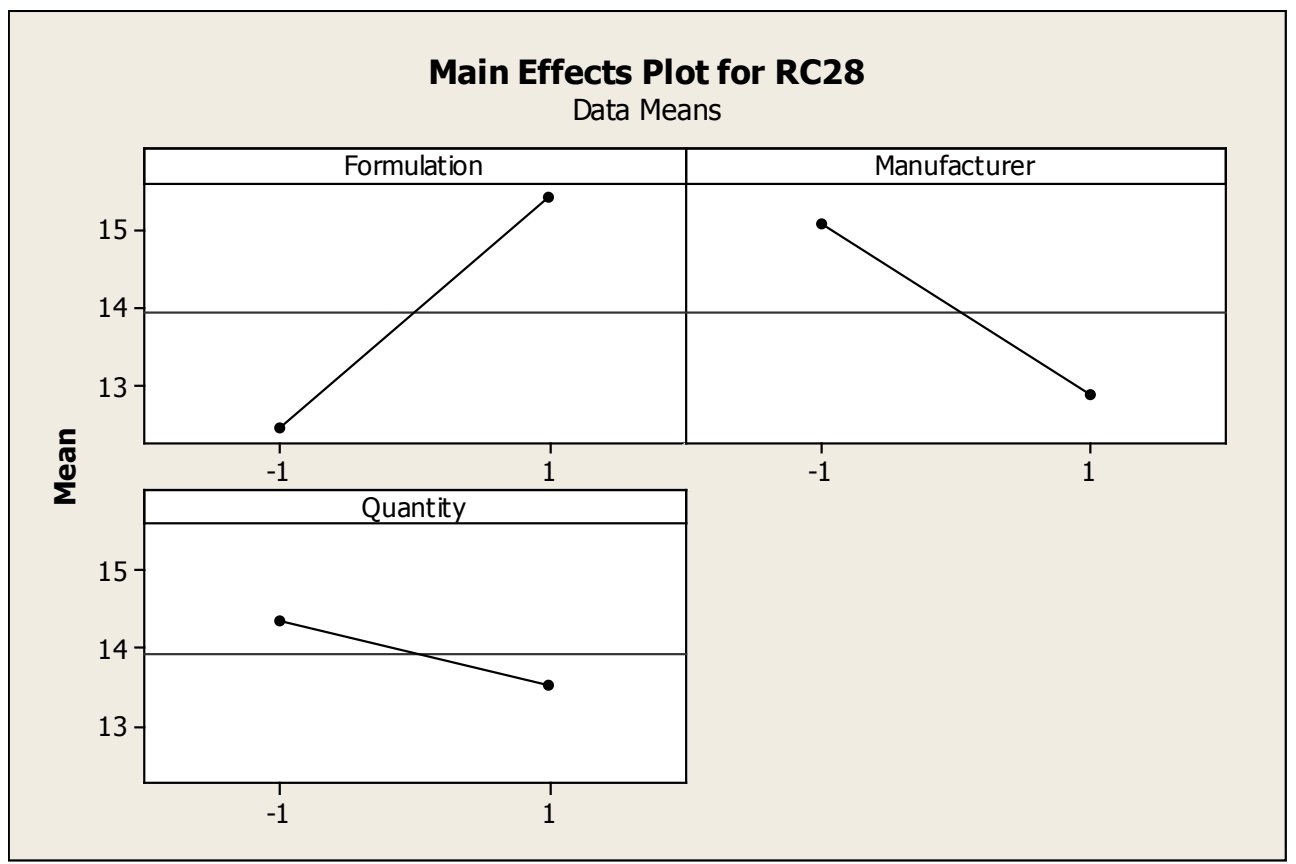

Figure 4. Set Retarder - Effect of each variable (factor) on compressive strength for a curing time of 28 days 


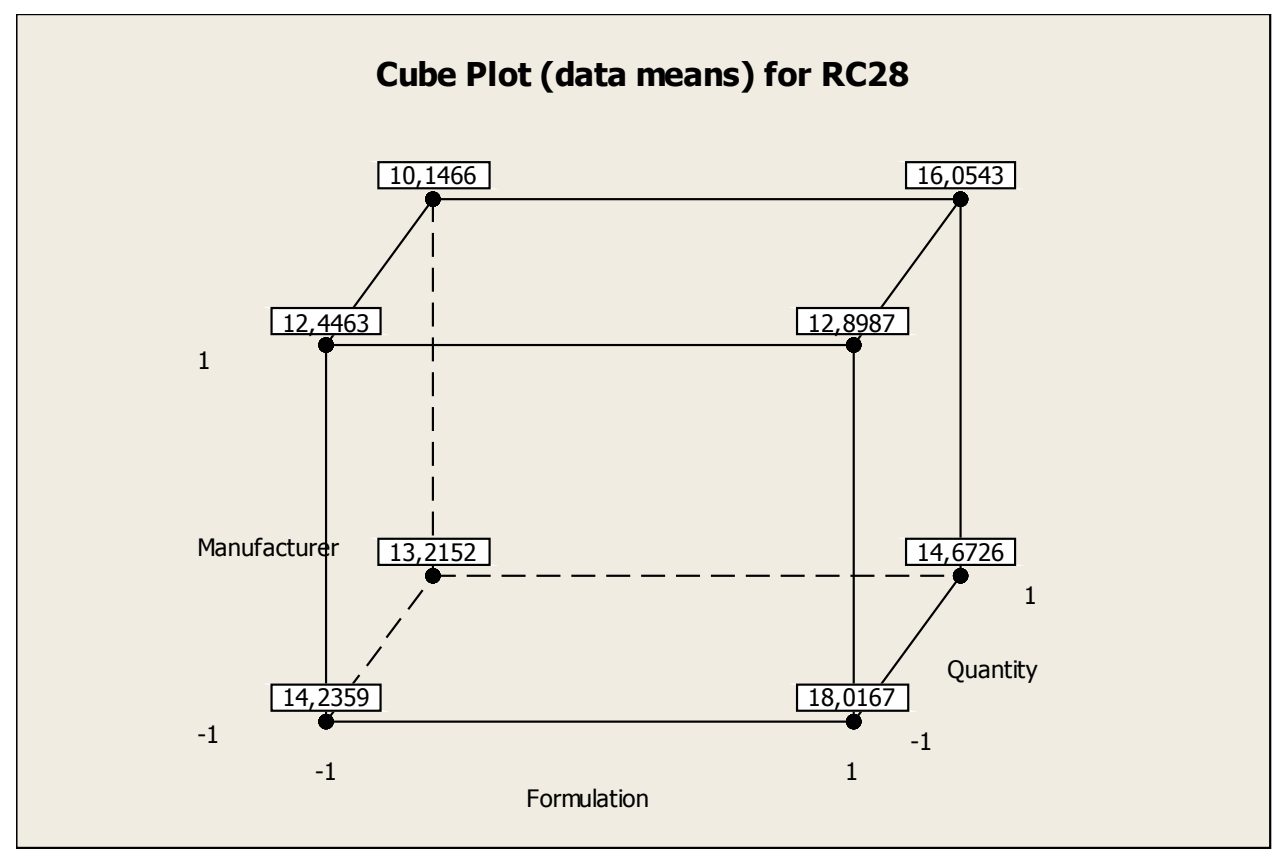

Figure 5. Set Retarder - Cube representing all the variables (factors) and the values of compressive strength for a curing time of 28 days.

\subsection{Accelerators}

The results obtained from compressive strength at age of 28 days test in products with accelerators are presented in Table 3 .

Table 3. Accelerators - Result of compressive strength at age of 28 days

\begin{tabular}{|c|c|c|c|c|}
\hline \multirow{2}{*}{ Test } & \multicolumn{3}{|c|}{ Variable } & \multirow{2}{*}{$\begin{array}{c}\text { Compressive } \\
\text { strength } 28 \text { days } \\
(\mathrm{MPa})\end{array}$} \\
\hline & Formulation & Quantity & Manufacturer & \\
\hline \multicolumn{4}{|c|}{ Blank (-) } & $14,7 \pm 3,1$ \\
\hline 1 & - & - & - & $17,3 \pm 1,9$ \\
\hline 2 & - & - & + & $14,6 \pm 2,8$ \\
\hline 3 & - & + & - & $17,0 \pm 1,6$ \\
\hline 4 & - & + & + & $15,6 \pm 1,8$ \\
\hline \multicolumn{4}{|c|}{ Blank (+) } & $24,3 \pm 1,4$ \\
\hline 5 & + & - & - & $19,1 \pm 2,1$ \\
\hline 6 & + & - & + & $20,5 \pm 4,2$ \\
\hline 7 & + & + & - & $25,5 \pm 1,5$ \\
\hline 8 & + & + & + & $15,1 \pm 5,1$ \\
\hline
\end{tabular}

The analysis of the effect of the factors in the compressive strength, when accelerators are used, is represented in the Fig. 6, 7, and 8. The factors Formulation and Manufacturer and the interactions: "manufacturer and quantity of accelerator". Also as shown in the table, the three factors having a significant effect on the compressive strength at age of 28 days, with a confidence interval of $95 \%$.

The use of accelerator of Manufacturer $\mathrm{S}$ and the Formulation B, which contains higher quantity of cement (Tests 5-8), had a positive effect on compressive strength at age of 28 days (Figure 8). The highest value was found for the combination of factors: Formulation B, greater amount of accelerators and Manufacturer S, and the lowest value was with the formulation A, less quantity of accelerators and manufacturer $\mathrm{H}$, as can be seen in the cube in Figure 8.

The effect of the addition of accelerators is positive for Formulation A, when compared with the Blank. For the Formulation B, only the value of compression strength of the mixture using higher quantity of the retarder from manufacturer S" was higher than the blank one. 


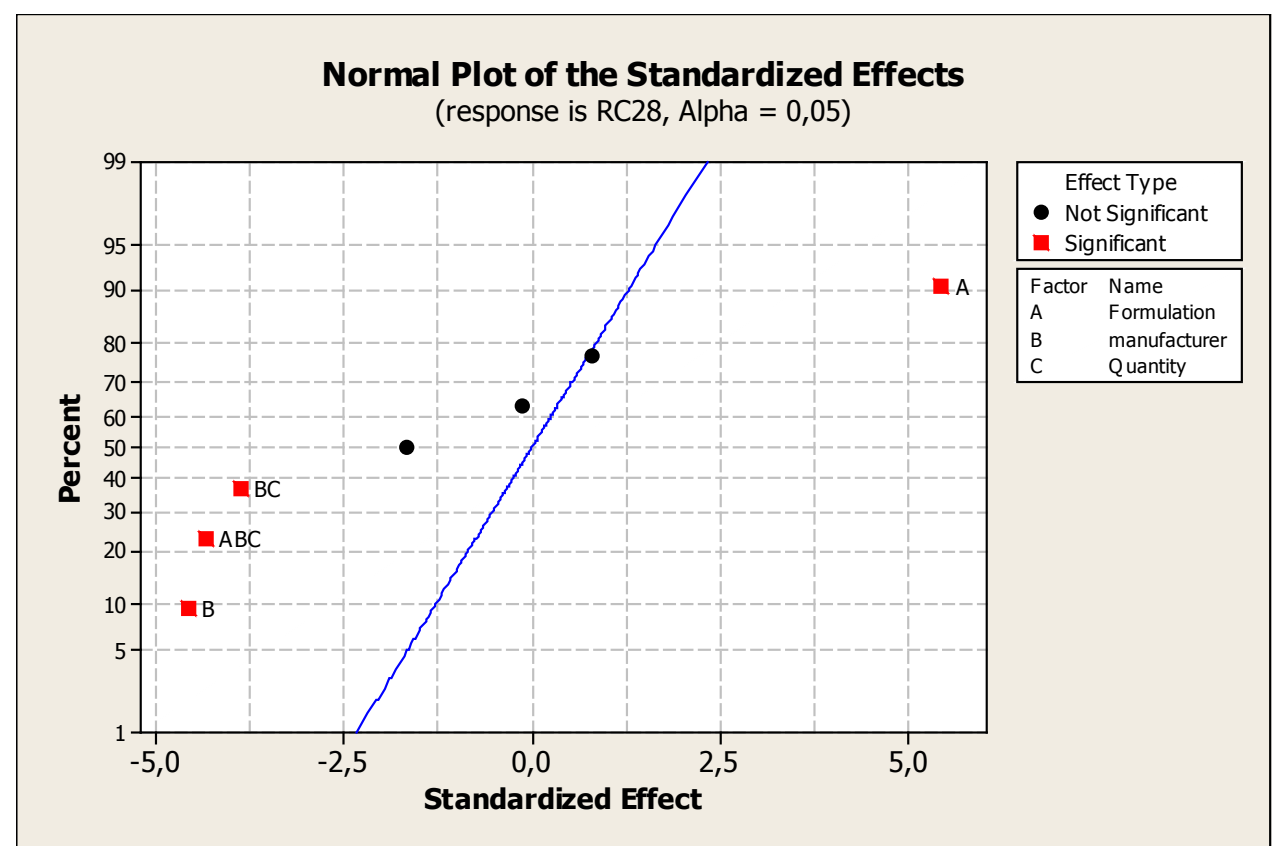

Figure 6. Accelerators - Analysis of the effects of the variables (factors) and their interactions on the compressive strength for a curing time of 28 days.

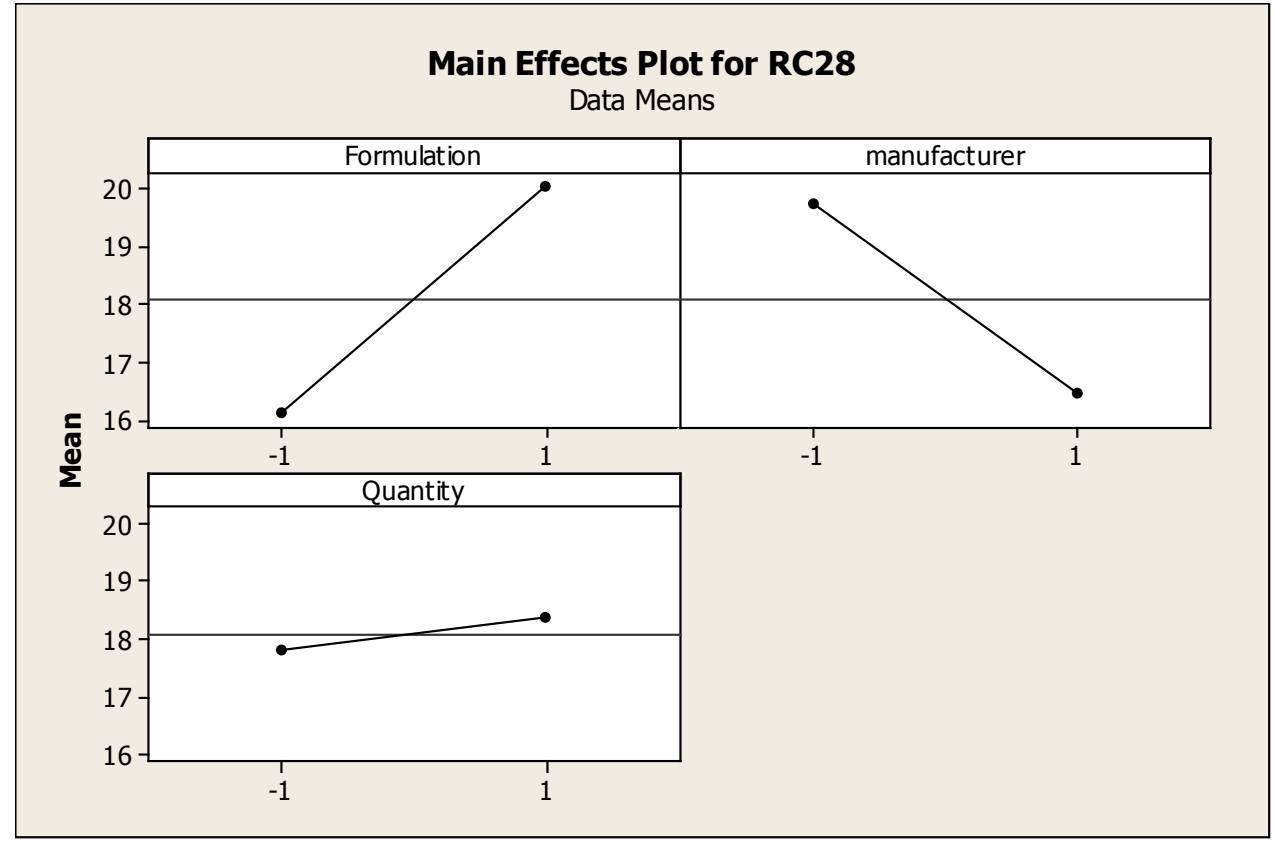

Figure 7. Accelerators - Effect of each variable (factor) in compressive strength for a curing time of 28 days. 


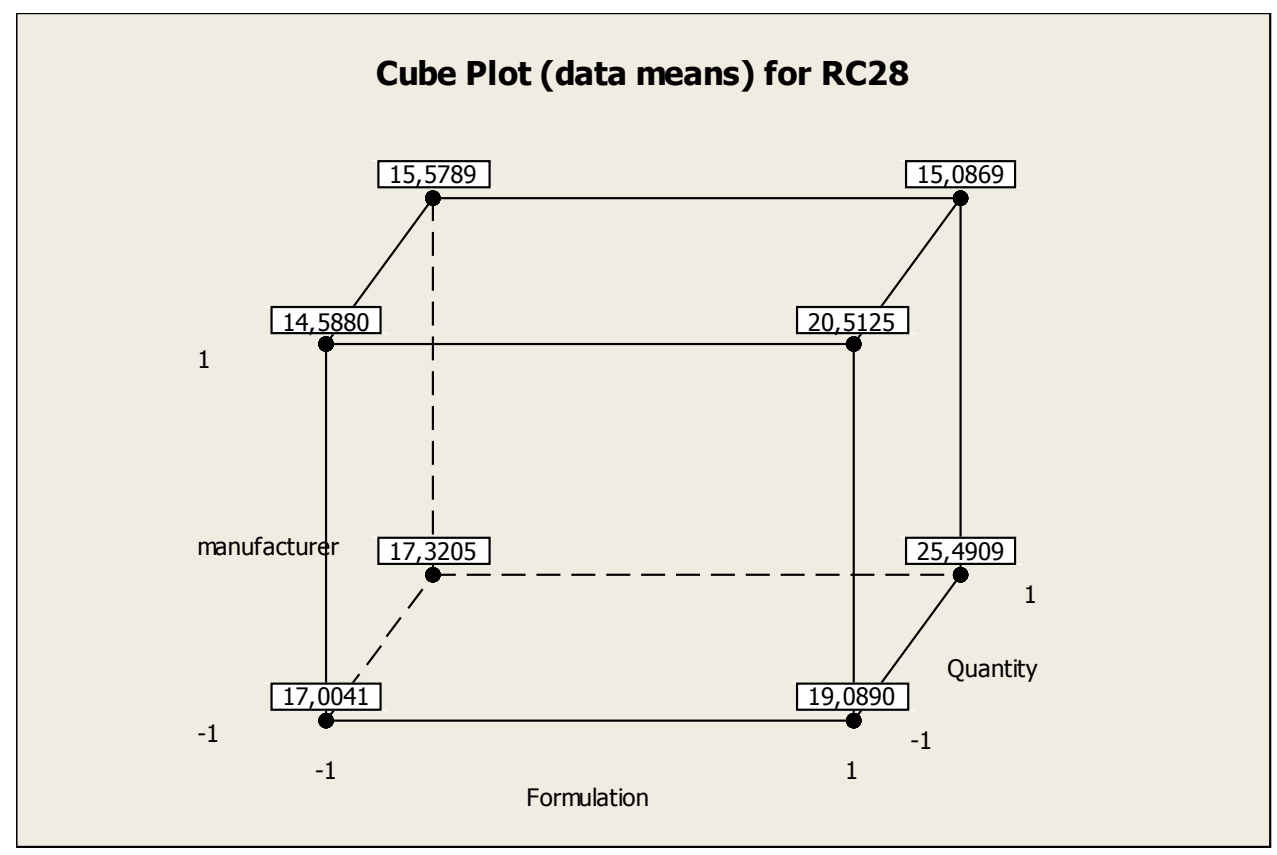

Figure 8. Accelerators - Cube representing all the variables (factors) and the values of compressive strength for a curing time of 28 days.

\subsection{Superplasticizer}

The results obtained from compressive strength at age of 28 days test in products with superplasticizer are shown in Table 4 .

Table 4. Superplasticizer - Result of compressive strength at age of 28 days.

\begin{tabular}{|c|c|c|c|c|}
\hline \multirow{2}{*}{ Test } & \multicolumn{3}{|c|}{ Variable } & \multirow{2}{*}{$\begin{array}{c}\text { Compressive } \\
\text { strength at } 28 \\
\text { days (MPa) }\end{array}$} \\
\hline & Formulation & Quantity & Manufacturer & \\
\hline \multicolumn{4}{|c|}{ Blank (-) } & $14,7 \pm 3,1$ \\
\hline 1 & - & - & - & $14,9 \pm 0,2$ \\
\hline 2 & - & - & + & $14,8 \pm 1,8$ \\
\hline 3 & - & + & - & $13,0 \pm 1,4$ \\
\hline 4 & - & + & + & $15,5 \pm 0,5$ \\
\hline \multicolumn{4}{|c|}{ Blank (+) } & $24,3 \pm 1,4$ \\
\hline 5 & + & - & - & $7,1 \pm 2,9$ \\
\hline 6 & + & - & + & $18,4 \pm 2,0$ \\
\hline 7 & + & + & - & $14,8 \pm 4,3$ \\
\hline 8 & + & + & + & $18,5 \pm 0,6$ \\
\hline
\end{tabular}

The studies to analyze the effects of factors on the compressive strength, when superplasticizers are used in mixtures, are represented in the Fig. 9, 10, and 11. It was concluded that, with a confidence interval of $95 \%$, both manufacturer and the quantity of superplasticizer have a significant effect on the compressive strength at age of 28 days. The same happens with the second order interactions: formulation and manufacturer; formulation and quantity of superplasticizer and among the three factors (formulation and manufacturer; formulation).

The samples that containing the largest quantity of superplasticizer from Manufacturer $\mathrm{H}$, had a positive effect on compressive strength at age of 28 days (Fig. 10). The highest value the compressive strength at age of 28 days was for the combination of factors: Formulation B, the smaller quantity of superplasticizer, manufacturer $\mathrm{H}$, and the lowest value for Formulation $B$, with less quantity of superplasticizer from Manufacturer S.

For the compressive strength at age of 28 days, the effect of adding superplasticizer is had a negligible effect for Formulation A, because the results are close to the Blank; however improving the workability and homogeneity of the pastes. In Formulation $B$, the effect of adding superplasticizer is negative, compared with the Blank. In this case, the effect in the workability was not so significant. 


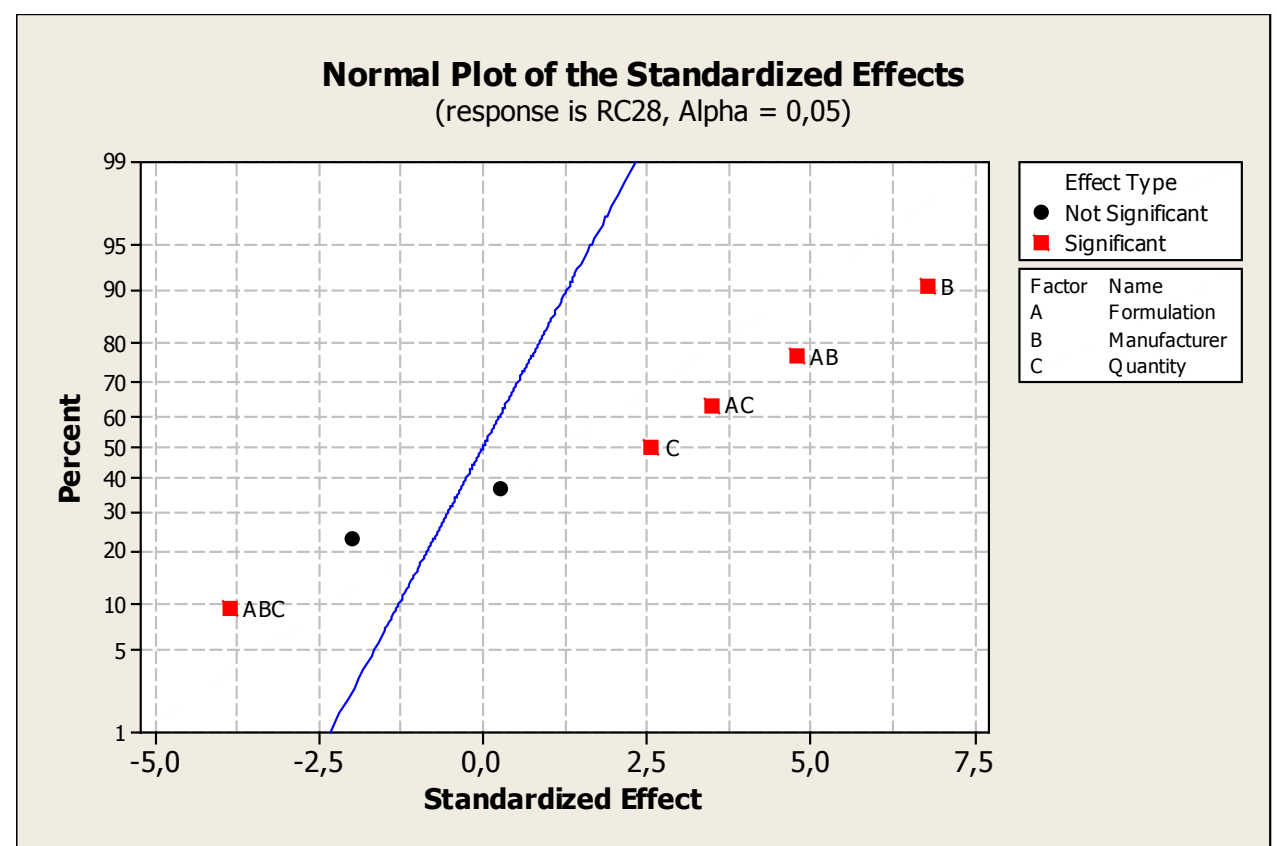

Figure 9. Superplasticizer - Analysis of the effects of the variables (factors) and their interactions on the compressive strength for a curing time of 28 days.

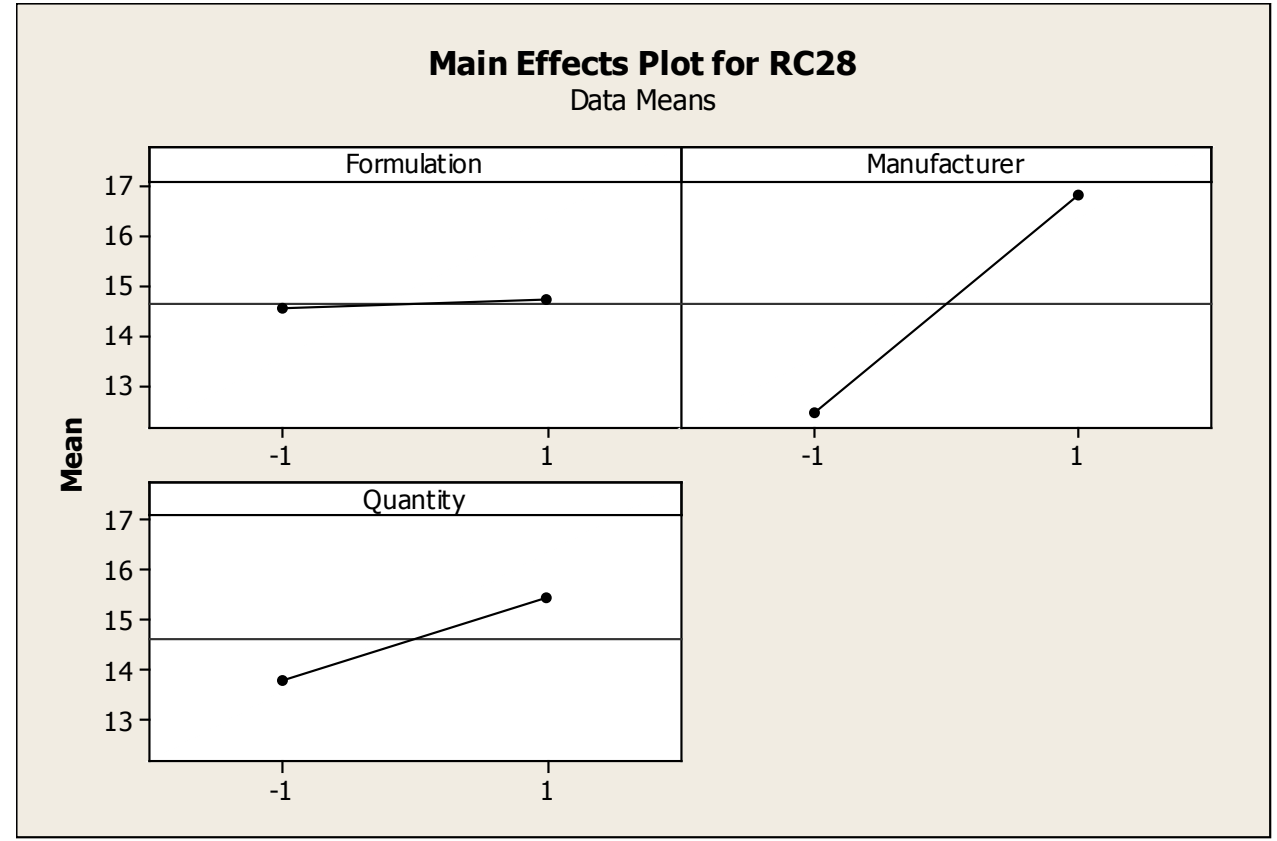

Figure 10. Superplasticizer - Effect of each variable (factor) in compressive strength for a curing time of 28 days. 


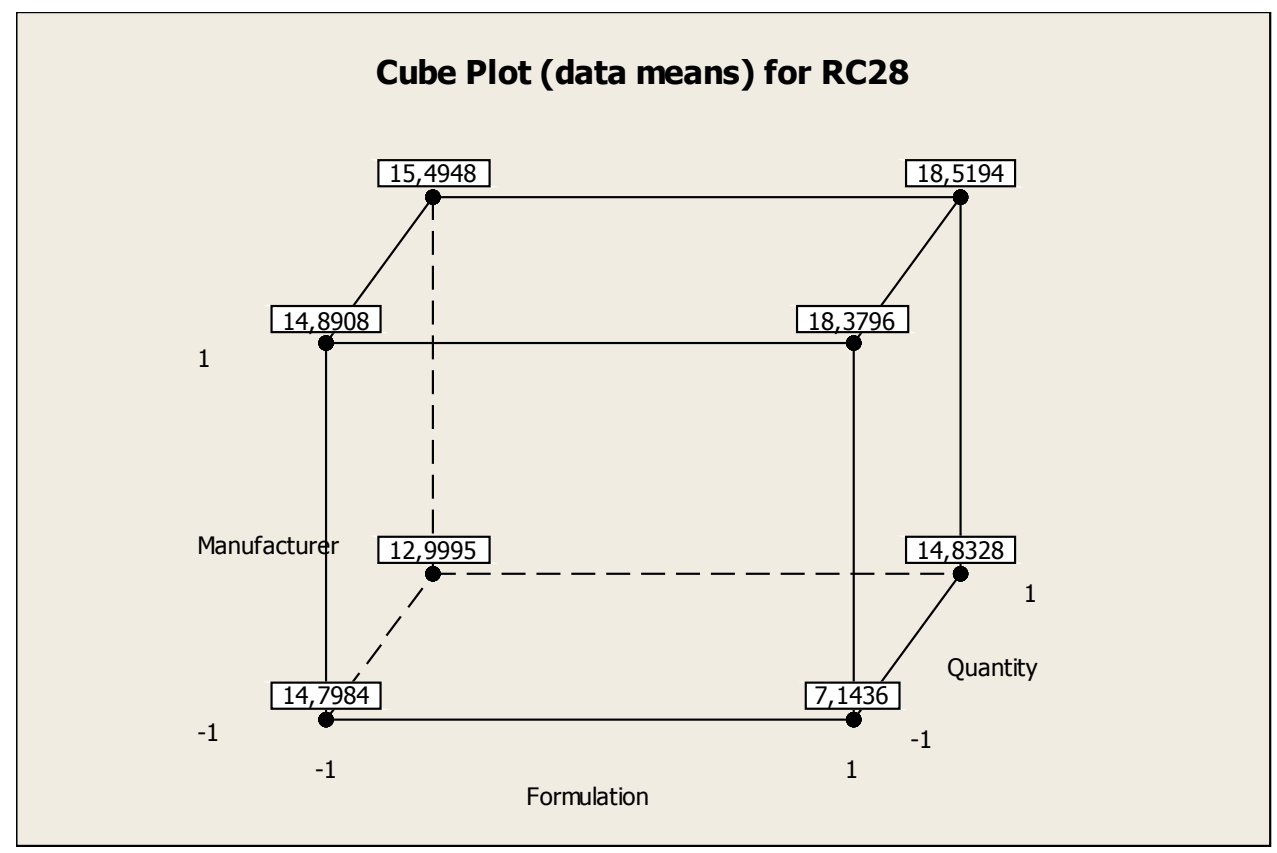

Figure 11. Superplasticizer - Cube representing all the variables (factors) and the values of compressive strength at age of 28 days

\section{Conclusions}

For use of the Formulation B and higher quantities of accelerator from Manufacturer $\mathrm{S}$ provided the best results for the compressive strength at age of 28 days. In general, the use of accelerators has a positive effect on this property.

As the evaporator concentrate contains boric acid, whose ion borate behaves as a retarder of the setting time, and the simulated waste has approximately $12.5 \%$ of boric acid, the addition of set retarders in the mixtures had a negative effect on the compressive strength, i.e., the values of compressive strength were reduced with their use.

The superplasticizer improved the workability and homogeneity of the pastes, but had no significant effect on the compressive strength at age of 28 days.

The next step is to evaluate the effect of these admixtures in other properties, including compressive strength at age of 90 days, viscosity, density, and setting time.

\section{Acknowledgements}

This work was performed at the Laboratory of Cementation CDTN - LABCIM. The authors would like to thank the help of Maria Judite Afonso Haucz, Francisco Donizete Cândido e Jaqueline A.A.Calábria, and CAPES, that support the student during the project.

\section{REFERENCES}

[1] TELLO, C. C. O. Efetividade das bentonitas na retenção de césio em produtos de rejeitos cimentados. Tese (Doutorado em Engenharia Química), Faculdade de Engenharia Química, Universidade Estadual de Campinas, Campinas, 2001.

[2] BRASIL. MCT. CTBI para o desenvolvimento Nacional. Plano de Ação 2007 - 2010. Brasília: MCT, 2007.

[3] ALVES, L. J. L. Seleção de uma formulação para tratamento de rejeitos de reator do tipo PWR por cimentação. Dissertação de Mestrado do programa de Pós-graduação em Ciências e Técnicas Nucleares da Escola de Engenharia da Universidade Federal de Minas Gerais, Belo Horizonte, 2001.

[4] INTERNATIONAL ATOMIC ENERGY AGENCY. Handling and Processing of Radioactive Waste from Nuclear Applications. Vienna: AIEA, 2001 (TECHNICAL REPORTS SERIES No.402).

[5] INTERNATIONAL ATOMIC ENERGY AGENCY. Improved cement solidification of low and intermediate level radioactive wastes. Vienna: AIEA, 1993 (TECHINICAL REPORTS SERIES, No. 350).

[6] COMISSÃO NACIONAL DE ENERGIA NUCLEAR. CNEN-NN-6.09: Critérios de aceitação para deposição de rejeitos radioativos de baixo e médio níveis de radiação. Rio de Janeiro, 2002 